\title{
Multicentric primary malignant melanomas of the choroid: two separate malignant melanomas of the choroid and two uveal naevi in one eye
}

\author{
H. E. VÖLCKER, AND G. O. H. NAUMANN \\ From the Department of Ophthalmology, University of Tübingen, Germany
}

SUMMARY Two completely separate malignant melanomas of the choroid occurred in 1 eye containing 2 additional uveal naevi. Review of the literature disclosed 7 further patients with unilateral multicentric malignant melanomas of the choroid and 11 bilateral multicentric malignant melanomas of the uvea. General aspects of multicentric primary neoplasia are discussed and an interpretation is attempted.

Multicentricity is a common feature of both unilateral and bilateral cases of retinoblastoma, whereas malignant melanomas of the uvea practically always occur as solitary lesions. The purpose of this report is to document the occurrence of 2 completely separate primary malignant melanomas of the choroid in an eye containing in addition 2 choroidal naevi.

\section{Case report}

A 63-year-old man complaining of decreased vision in his left eye was found to have a pigmented tumour of the choroid on the temporal side. His visual acuity was 0.3 ; intraocular pressure in both eyes was $17 \mathrm{mmHg}$ by applanation. Within 4 weeks the lesion increased in size, and the eye was therefore enucleated. The other eye did not show any pathological changes. Thorough general examination in the department of internal medicine and dermatology did not reveal any other tumour or neoplasia. There was no history of cancer or neurofibromatosis in the family. Vitiligo was not present.

\section{PATHOLOGY}

The left globe was firm and measured $23 \times 23 \times 23$ $\mathrm{mm}$, the cornea $11 \times 11.5 \mathrm{~mm}$, and the optic nerve $5 \mathrm{~mm}$. Transillumination of the globe with intensive light diaphanoscopy revealed 3 distinctly separate shadows. The first opacity was localised between 2 and 4 o'clock, $10 \mathrm{~mm}$ behind the limbus and about

Address for reprints: Professor G. O. H. Naumann, Department of Ophthalmology, University of Tübingen, Germany
$4 \mathrm{~mm}$ from the optic nerve; its diameter was $18 \mathrm{~mm}$ (MM 1 in Figs. 1 and 2). On the opposite side of the limbus between 8.30 and 9.30 there was an isolated shadow $7 \mathrm{~mm}$ behind the limbus showing an oval configuration with a diameter of $9 \mathrm{~mm}$. Inferiorly at 5 o'clock there was an oval area of opacification with a maximal diameter of $6 \mathrm{~mm}$ (naevus 1 in Fig. 1).

The globe was opened horizontally, and the middle segment was sectioned in such a way as to include the optic nerve and both shadows (MM1

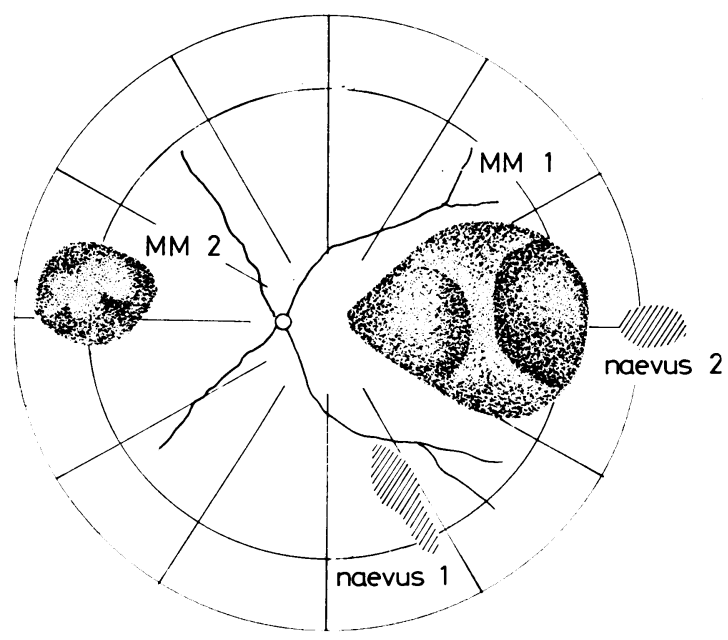

Fig. 1 Sketch of the fundus of an eye containing 2 separate malignant melanomas of the choroid (MMI and MM2) in addition to 1 naevus of the choroid (naevus 1) and 1 naevus of the ciliary body (naevus 2) 


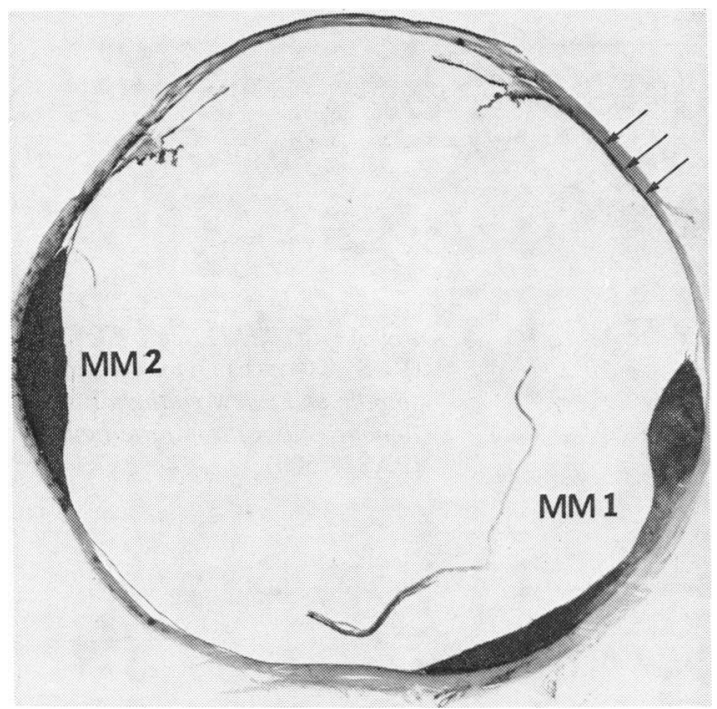

Fig. 2 Horizontal sections with 2 malignant melanomas of the choroid MM1 and MM2. The retina is artificially detached and there is a naevus of the pars plana (arrows). Path.-Anatom. Labor der Univ.-Augenklinik Tübingen, No. 17324. ( $H$ and $E \times 3.5)$ and MM2). The cut surface of the lower calotte presented an additional pigmented area at the level of the pars plana which was not connected with the neighbouring MM1.

In horizontal section the cornea and anterior chamber angle were found to show nothing remarkable. The iris was moderately atrophic and showed a few melanophages close to the sphincter pupillae, while the ciliary body was degenerate in the region of the pars plicata, with moderate atrophy of the ciliary muscle.

The retina showed cystoid degeneration at the periphery and was detached by 2 completely separate pigmented flat tumours of the choroid. The retina overlying the tumour showed microcystoid changes and a few lipofuscin granules. The choriocapillaris overlying the larger tumour was obliterated, but Bruch's membrane was preserved (Fig. 2).

Tumour MM1. This choroidal tumour showed 2 prominent portions connected by a flatter partially necrotic area. The tumour consisted of spindle and epithelioid cells with oval nuclei, prominent nucleoli, and many mitoses. The inner layer of the sclera was invaded by tumour cells extending along emissary canals to produce an epibulbar extension. The
Fig. 3 Malignant melanoma of the choroid, MMI. (a) View of entire lesion invading and perforating the sclera (arrows). (b) Cytology showing spindle and round epithelioid tumour cells. $($ PAS $\times 500)$

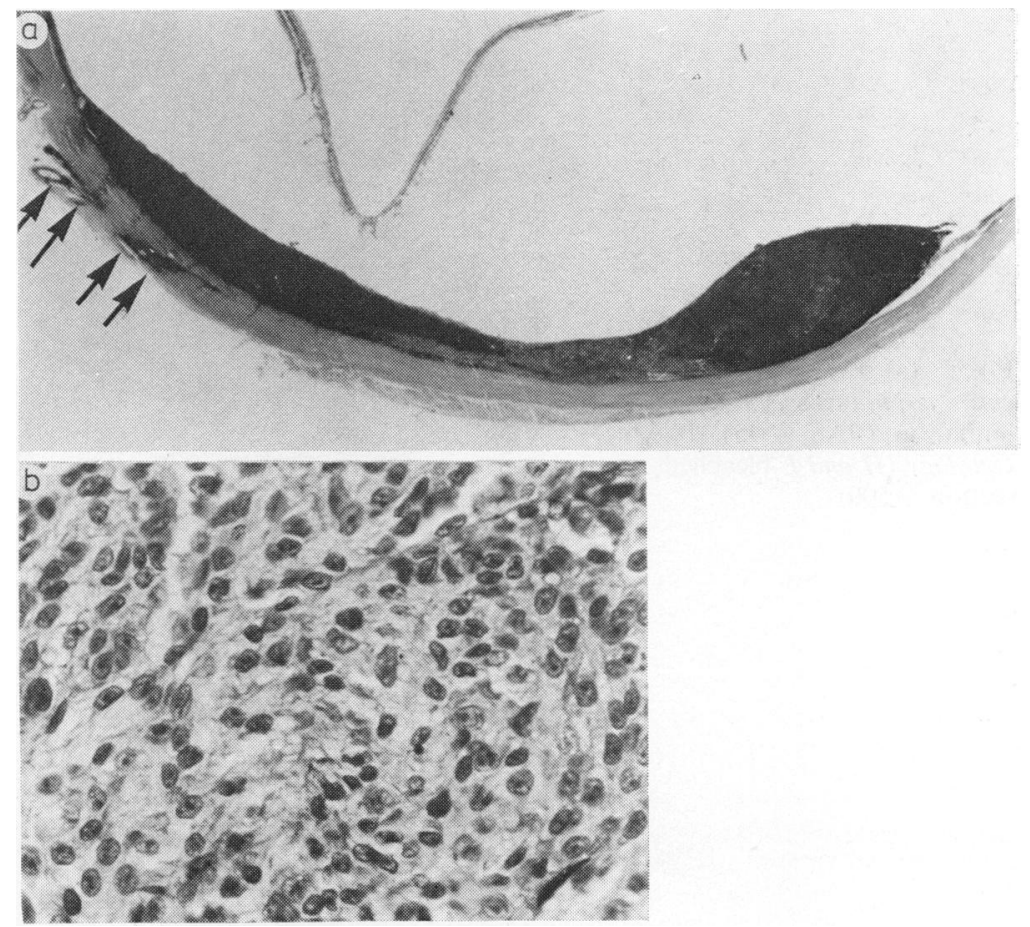



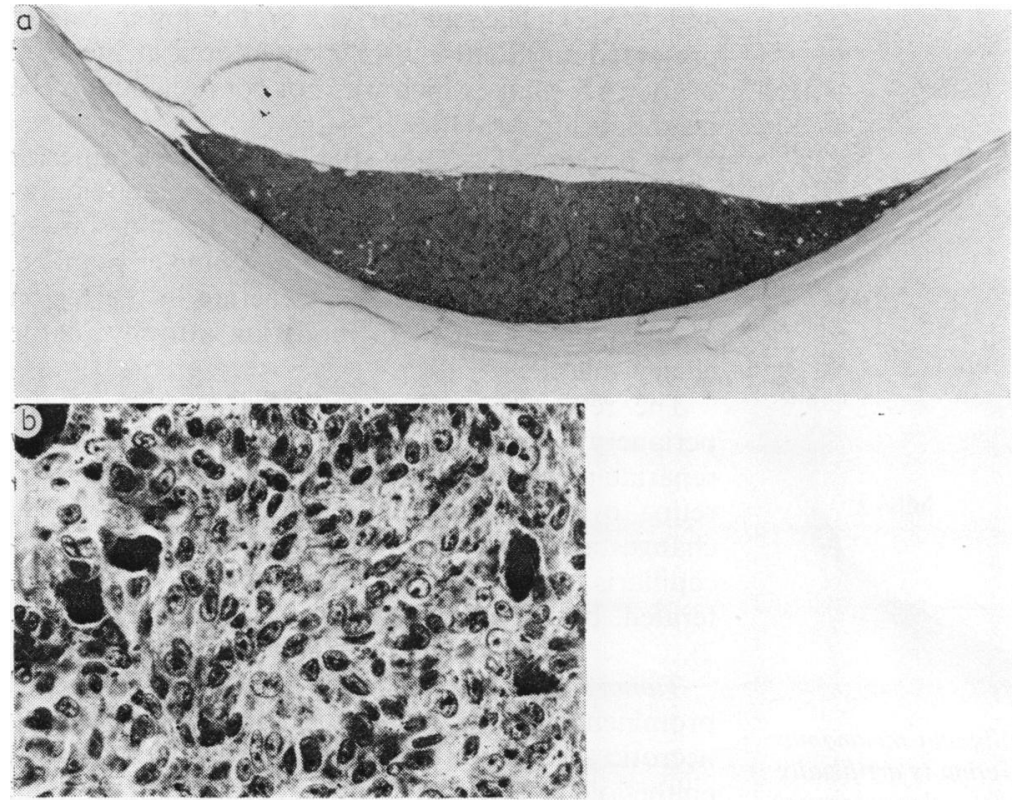

Fig. 4 (a) MM2: entire lesion (PAS $\times 10$ ). (b) Cytology showing spindle and a few epithelial tumour cells with mitotic figures. $(\mathrm{PAS} \times 500)$

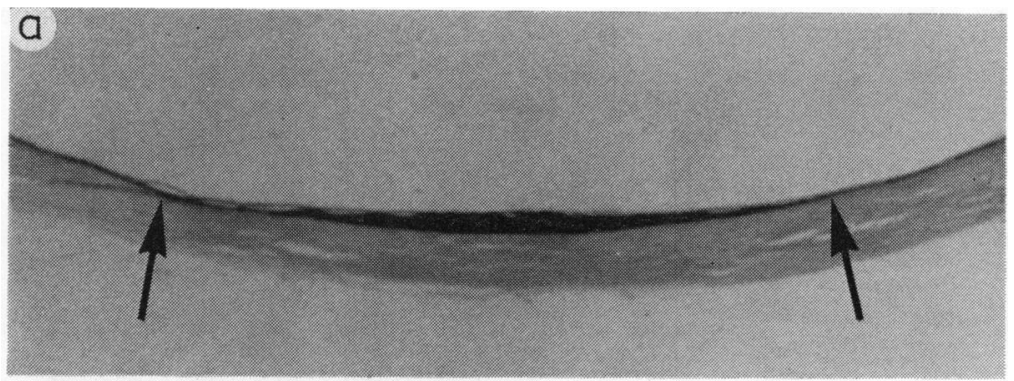

Fig. 5 (a) Naevus of the choroid: entire lesion (arrows $=$ limitation) (PAS $\times 45)$. (b) Cytology ( $H$ and $E$ bleached section $\times 500$ )

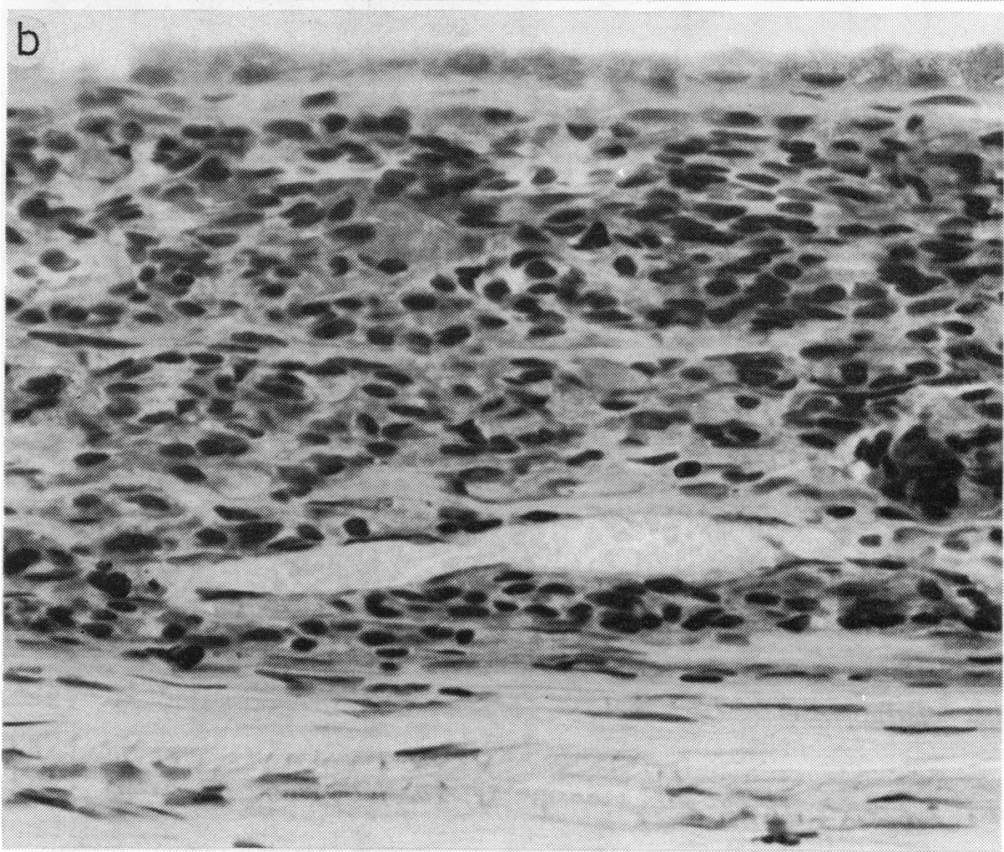


peripheral portions of this larger tumour and its base contained a few fusiform naevus cells (Fig. 3).

Tumour MM2. This irregularly pigmented choroidal tumour likewise consisted of spindle and epithelioid cells with oval nuclei and prominent nucleoli. The tumour was invading the inner layers of the sclera but there was no epibulbar spread (Fig. 4). Serial sections failed to show any connection between the two lesions.

Naevus 1. Vertical sections through the pigmented spot in the lower calotte showed a circumscribed thickening of the choroid. It consisted of fusiform spindle cells with small slender nuclei and pronounced pigmentation. Neither the choriocapillaris, Bruch's membrane, pigment epithelium, nor the sensory retina showed any abnormality. There were no melanocytic tissue strands alongside the naevus (Fig. 5).

Naevus 2. The most peripheral choroid and adjacent pars plana of the ciliary body showed a thickening of the uvea caused by slender spindle naevus cells with moderate melanin content. The optic nerve showed nothing remarkable (Fig. 6).

In vertical sections through upper calotte there were no melanocytic tissue strands visible in the uvea or elsewhere.

\section{DIAGNOSES}

(1) Two multicentric primary malignant melanomas of 1 choroid, both of mixed cell type. (2) Collateral retinal detachments, with secondary degenerative changes in the retina overlying the two malignant melanomas. (3) Two naevi of the choroid.

\section{Discussion}

Primary multicentric tumours occur in 0.8 to $2 \%$ of patients (Fischer, 1949). Jensen (1963), in his study of malignant melanomas of the uvea, found 4 to $6 \%$ of patients to have additional primary cancers elsewhere in the body. Naumann and co-workers (1966) and Naumann (1970) described multiple
Fig. 6 (a) Naevus of the pars plana of the ciliary body (arrows $=$ limitation). (PAS $\times 14)$. (b) Cytology with enlargement. (PAS $\times$ 500)
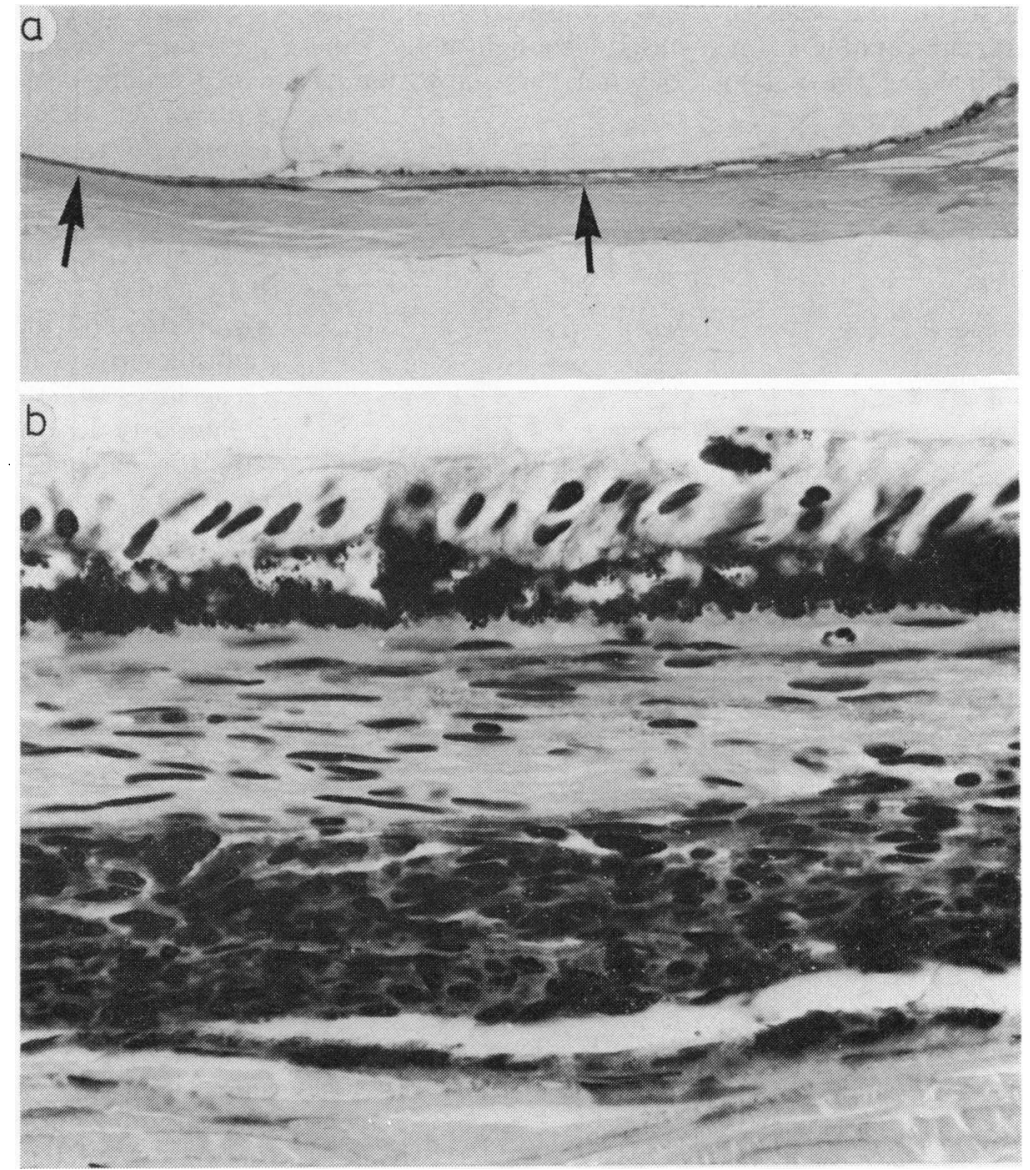
naevi of the choroid in $2 \%$ of cases studied histopathologically and clinically. Separate bilateral malignant melanomas of the choroid have been reported. Blodi (1976) calculated their frequency in a general population of 200 million with an average 72 years life expectancy as being about 1 case every 18 years. Altogether we found 11 cases in the literature and have personally (G.N.) observed an additional case since 1974 (Table 1). Multicentric malignant melanomas of the uvea in the same eye appear to be even rarer than bilateral malignant melanomas (Table 2).

Billroth (1889) suggested the following criteria to establish the multicentricity of a given cancer: (1) Same tissue of origin; (2) histologically separate structure; (3) capacity to lead to metastasis. According to these criteria both the present malignant melanomas originated from the choroid of 1 eye. The cytological features were not appreciably different, though 1 of them showed more aggressive growth with perforation of the sclera. The second malignant melanoma was more pigmented than the first. On the basis of their cytology both tumours appear capable of metastasis, although at the time of writing the patient does not show any sign of

\section{Table 1 Case reports of bilateral choroidal melanomas}

\begin{tabular}{ll}
\hline ten Doeschate & $(1919)$ \\
Shine & $(1930)$ \\
Cordes and Cook & $(1949)$ \\
Wiesinger et al. & $(1959)$ \\
Tade & $(1960)$ \\
Buschmann and Goder & $(1964)$ \\
Machemer & $(1966)$ \\
Timm & $(1966)$ \\
Bietti and Vozza & $(1968)$ \\
Shammas and Watzke & $(1977)$ \\
\hline
\end{tabular}

Table 2 Case reports of multicentric malignant melanomas of the choroid in 1 eye

\begin{tabular}{lll}
\hline Fuchs & $(1882)$ & 1 case \\
Velhagen & $(1920)$ & 1 case \\
Rochat & $(1926)$ & 1 case \\
Pressburger & $(1927)$ & 1 case \\
Rosen and Moulton & $(1953)$ & 1 case \\
Ley and Wahl & $(1963)$ & 1 case \\
Condon and Mullaney & $(1967)$ & 1 case \\
\hline
\end{tabular}

distant metasatases. Consequently, we have no doubt that both malignant melanomas are two independent primary cancers arising in 1 eye.

Other explanations for the occurrence of 2 such lesions appear to us to be extremely unlikely.

For instance, the 2 distinct malignant melanomas of the choroid could theoretically be considered to be a metastasis from the other. However, the lack of other metastases in the body would seem to be a strong argument against such an explanation, as are the lack of lymph vessels within the eye and the location of the 2 malignant melanomas within separate provinces of the choroidal vasculature. The apparently normal uvea of the other eye makes this an unlikely source of metastatic tumour. Again, both the clinical findings and the histology would argue against the hypothesis that 1 or both of the choroidal malignant neoplasms was a metastasis of a cutaneous malignant melanoma (Font et al., 1967).

Again, general factors might predispose to neoplasia, but a search for such factors to explain the occurrence of 2 separate primary malignant melanomas of the choroid revealed no evidence of von Recklinghausen's neurofibromatosis (Goldstein and Wexler, 1930). Neither was there any history of exposure to carcinogenic chemicals such as hydrazine and dimethylsulphate, which have been shown capable of inducing malignant melanomas of the choroid (Albert and Puliafito, 1977). Nor does the patient suffer from any detectable immune deficiency syndrome, and there was no history of exposure to radiotherapy in the area of the head or elsewhere (Kogelnik, 1977). In view of the multicentricity of melanocytic lesions in 1 eye we also looked specifically for evidence of an immunological response expressing itself as vitiligo (Lerner et al., 1977). Since uveal tumours have been induced by oncogenic viruses (Albert and Puliafito, 1977) it is tempting to speculate that a virus may have been involved in the development of the 2 separate tumours in this eye, though there is no direct evidence in the present case to substantiate a viral aetiology. Finally, there was no definite family history of a genetic predisposition to malignant neoplasia (Tasman, 1970; Lynch et al., 1968).

As to the relationship to uveal naevi, the occurrence of multiple naevi in the choroid is not unusual. Naumann and co-workers $(1966,1971)$ and Naumann (1970) observed it in about $2 \%$ of their patients examined clinically and histopathologically, while Gass (1977) noted multiple lesions fulfilling his criteria for uveal naevi. The additional finding of naevi in this particular eye would fit the thesis of Yanoff and Zimmerman (1967) that most malignant melanomas of the uvea originate in uveal naevi. 
The risk of an additional tumour developing in a patient suffering from a primary malignant uveal tumour is very small. However, this case and those reported elsewhere remind us that careful examination is always indicated to rule out such an additional tumour.

\section{References}

Albert, D. M., and Puliafito, C. A. (1977). Choroidal melanoma: possible exposure to industrial toxins. New England Journal of Medicine, 296, 634-635.

Bietti, G., and Vozza, R. (1968). Melanoblastoma bilaterate della coroide. Clinica Oculistica, 12, 52-61.

Billroth, T. (1889). Allgemeine chirurgische Pathologie und Therapie. Quoted by Buschmann, W., and Goder, G. (1964). Reimer: Berlin.

Blodi, F. (1976). Bilateral choroidal melanoma. Verhoeff Society 1976, Washington, DC 26-28 April.

Buschmann, W., and Goder, G. (1964). Das doppelseitige maligne Melanoblastom der Aderhaut. Albrecht v. Graefes Archiv für Ophthalmologie, 167. 225-238.

Condon, R. A., and Mullaney, J. (1967). Multiple malignant melanoma of the uveal tract in one eye. British Journal of Ophthalmology, 51, 707-711.

Cordes, F. C., and Cook: R. D. (1949). Simultaneous bilateral primary ocular malignant melanoma. Transactions of the American Ophthalmological Society, 47, 80-92.

Doeschate, G. ten (1919). Über metastatische Sarkome am Auge. Nederlands Tijdschrift voor Geneeskunde, 2, 1432. Quoted by Buschmann. W., and Goder, G. (1964).

Fischer, W. (1949). Krebsfragen. Fischer: Jena. Quoted by Buschmann, W., and Goder, G. (1964).

Font, R. L., Naumann, G., and Zimmerman, L. E. (1967). Primary malignant melanoma of the skin metastatic to the eye and orbit. Report of ten cases and review of the literature. American Journal of Ophthalmology, 63, 738754.

Fuchs, E. (1882). Das Sarkom des Uveal-Tractus. Quoted by Rosen, D. A., and Moulton, G. N. (1953) Braumüller: Vienna.

Gass, J. D. M. (1977). Problems in the differential diagnosis of chorioidal nevi and malignant melanomas. American Journal of Ophthalmology, 83, 299-323.

Goldstein, I., and Wexler, D. (1930). Melanosis uveae and melanoma of the iris in neurofibromatosis (Recklinghausen). Archives of Ophthalmology, 3, 288-296.

Jensen, O. A. (1963). Malignant melanomas of the uvea in Denmark 1943-1952: a clinical, histopathological and prognostic study. Acta Ophthalmologica, Supplementum $75,73$.

Kogelnik, H. D. (1977). Über die Häufigkeit von Zweittumoren nach chirurgischer und strahlentherapeutischer Behandlung. Strahlentherapie, 153, 163-167.
Lerner, A. B., Nordlund, J. J., and Albert, D. M. (1977). Pigment cells of the eyes in people with vitiligo. New England Journal of Medicine, 296, 232.

Ley, A. P., and Wahl, J. W. (1963). Multiple malignant melanoma of the choroid. Archives of Ophthalmology, 70, 385-386.

Lynch, H. T., Anderson, D. E., and Krush, A. J. (1968). Heredity and intraocular malignant melanoma: study of two families and review of forty-five cases. Cancer, 21, 119-125.

Machemer, R. (1966). Zur Pathogenese des flächenhaften Melanoms. Klinische Monatsblätter für Augenheilkunde, 148, 641-652.

Naumann, G. O. H., Yanoff, M., and Zimmerman, L. E. (1966). Histogenesis of malignant melanomas of the uvea: I. Histopathologic characteristics of nevi of the choroid and ciliary body. Archives of Ophthalmology, 76, 784-796.

Naumann, G. O. H., Hellner, K., and Naumann, L. R. (1971). Pigmented nevi of the choroid: clinical study of secondary changes in the overlying tissues. Transactions of the American Academy of Ophthalmology and Otolaryngology, 75, 110-123.

Naumann, G. O. H. (1970). Pigmentierte Naevi der Aderhaut und des Ciliarkörpers. Advances in Ophthalmology, 23, 187-272.

Pressburger, E. (1927). Über den Befund von zwei Sarkomen der Aderhaut in einem Augapfel. Bericht der Deutschen Ophthalmologischen Gesellschaft, 46, 451-455.

Rochat, G. F. (1926). Zwei gleichgrosse Sarkome in einem Auge. Klinische Monatsblätter für Augenheilkunde, 76, 651-655.

Rosen, D. A., and Moulton, G. N. (1953). Multiple malignant melanomas in one eye. American Journal of Ophthalmology, 36, 73-75.

Shammas, H. F., and Watzke, R. C. (1977). Bilateral choroidal melanomas. Archives of Ophthalmology, 95, 617-623.

Shine, F. W. (1930). Report of a case of bilateral sarcoma of the uvea. New York Eye and Ear Information, 1, 31-33.

Tade, A. A. (1960). Bilateral primary melanoblastoma of the choroidea (Russian). Vestnik Oftalmologii, 73, 30-35.

Tasman, W. (1970). Familial intraocular melanoma. Transactions of the American Academy of Ophthalmology and Otolaryngology, 74, 955-958.

Timm, G. (1966). Zur Klinik, Morphologie und Genese doppelseitiger intraokularer Melanozytoblastome. 2. Kongr. europ. Ges. Ophthal. Wien 1964; Ophthalmologica, Additamentum ad vol. 151, 643-646.

Velhagen, C. (1920). Úber den Befund von zwei Choroidalsarkomen in einem Augapfel. Klinische Monatsblätter für Augenheilkunde, 64, 252-255.

Wiesinger, H., Phipps, G. W., and Guerry, D. (1959). Bilateral melanoma of choroid associated with leukemia and meningiome. Archives of Ophthalmology, 62, 889-893.

Yanoff, M., and Zimmerman, L. E. (1967). Histogenesis of malignant melanomas of the uvea: II. Relationship of uveal nevi to malignant melanomas. Cancer, 20, 493-507. 